\title{
HLA-B*27 subtypes and its clinical implications characterization by studying sequence-specific alleles
}

\author{
Narotam Sharma ${ }^{1 *}$, Mohd Anas ${ }^{2}$, Ahmad Rabbani $^{3}$, Priyam Bharti ${ }^{3}$, Shitanshu Kaundal ${ }^{4}$, Vijay Kumar ${ }^{1}$, Bhageshwari Mahato ${ }^{1}$ \\ ${ }^{1}$ Central Molecular Research Laboratory, Department of Biochemistry, Shri Guru Ram Rai Institute of Medical and Health Sciences, Shri Guru Ram Rai \\ University, Dehradun, India \\ ${ }^{2}$ Department of Biosciences, Shri Ram College, Muzaffarnagar, India \\ ${ }^{3}$ Department of Microbiology, Baba Farid Institute of Technology, Dehradun, India \\ ${ }^{4}$ Department of Microbiology, Shri Dev Suman Subharti Medical College, Ras Bihari Bose Subharti University, Dehradun, India
}

\begin{tabular}{l}
\hline ARTICLE INFO \\
\hline Article history: \\
Received on: December 01, 2018 \\
Accepted on: February 07, 2019 \\
Available online: July 04, 2019 \\
\hline
\end{tabular}

Key words:

PCR, sequence-specific alleles, amplicon, ankylosing spondylitis, rheumatoid arthritis factor, human leukocyte antigen.

\begin{abstract}
Ankylosing spondylitis (AS) is a form of spondylitis in which spine is affected primarily along with other joints. The vertebrae fuse together and form a rigid structure. Individuals with AS are also positive for human leukocyte antigen (HLA) B-27. One hundred and eighty-three symptomatic patients of AS were used in the study. Sequence-specific priming (SSP) PCR technique was used to detect the HLA B-27 specific allele. This study showed (out of 183 suspected cases, 45 cases were detected positive with HLA B-27 allele, while the remaining 138 were negative) that the positivity rate for AS with HLA B-27 allele is less. In 183 cases, 63 were females, whereas 7 cases were positive and 56 negative, whereas 38 cases were positive for male and 82 cases were negative. When sample was analyzed in term of age groups, it was found that out of 45 positive samples, the positivity rate was maximum, i.e., $57.14 \%$ in the patient above 37 years of age. Furthermore, it was observed that the males above 30 years are more prone to develop AS with HLA B27 specific allele. For the diagnosis of AS, conventional PCR technology is a promising diagnostic method and can be considered as an important tool along with other diagnostics parameters.
\end{abstract}

\section{INTRODUCTION}

The human leukocyte antigen (HLA) system or HLA complex is a cluster of gene complex encoding the major histocompatibility complex protein in human [1]. The genes present on the short arm of chromosome number 6 control HLA expressions. The HLA antigen has an essential role in the control of self-recognition, and thus defends against microorganisms [2]. It is one of the most polymorphic genetic systems in human beings. The polymorphic proteins of HLA vary in peptides they can bind and thus determine the nature of the peptides the body can mount an immune response [3]. Ankylosing spondylitis (AS) is considered by axial arthritis connecting sacroiliac joints and spine, peripheral arthritis, enthesis with extra-articular features such as uveitis, inflammatory bowel

\footnotetext{
*Corresponding Author

Narotam Sharma, Central Molecular Research Laboratory, Department of Biochemistry, Shri Guru Ram Rai Institute of Medical and Health Sciences, Shri Guru Ram Rai University, Dehradun, India. E-mail: sharmanarotam5@gmail.com
}

disease, and psoriasis. HLA has six polymorphic genes (HLA-A, HLA-B, HLA-C, HLA-DP, HLA-DQ, and HLA-DR). HLA-A, HLA-B, and HLA-C belong to HLA class 1 molecules that bind and present a range of intracellular peptides to cytotoxic CD8+ T cells [4]. It also controls the innate immune responses of our body and thus is a significant component of our immune system. They are expressed on the surface of almost all nucleated cells and are composed of 45-kd glycoprotein heavy chain with three domains which are non-covalently associated with b-2 microglobulin which provides structural support to the heavy chain [5]. The HLA class 1 molecule lies on the cell surface and a portion of it is inserted into the lipid bilayer of the plasma membrane and has a small cytoplasmic tail. HLA-DP, HLA-DQ, and HLADR belong to HLA class 2 molecules [6]. They are expressed only on B-lymphocytes, antigen-presenting cells (monocytes, macrophages, and dendritic cells), and activated $\mathrm{T}$ lymphocytes [7]. Class 2 genes yield heterodimers of two noncovalent associated glycosylated polypeptide chains which are composed of alpha and beta. Antigens to $\mathrm{CD}^{4+} \mathrm{T}$ cells are presented by HLA class 2 
molecules. Appearance of HLA class 2 on cells, which normally do not express them, stimulated by cytokines like interferon $\mathrm{G}$ and in a transplant, it is associated with acute graft rejection [8]. Role of HLA class 2 molecules is to initiate a general immune response and it the reason why they need to be only present on immunologically active cells, B-lymphocytes, and macrophages [9]. Encoded by a 4-Mb region of human chromosome 6 p21 and it is the most variable region in the human genome [10]. HLA system is the major histocompatibility system relevant for matching for transplantation and its indication comes from the fact that kidney or bone marrow grafts exchanged between HLA identical siblings survive, with appropriate immunosuppressive treatment, almost as well as those between identical twins are far better than grafts exchanged between mismatched siblings or other relatives [11]. This is because the loci controlling all HLA determinants are closely linked within the HLA area [12]. Identical unrelated donors and recipients for HLA-A, B, C, and D region determinants have a significant effect on graft survival [13]. A haplotype is the set of HLA antigens inherited from one parent [14]. Nearly all the subtypes are related to AS. In addition to $B * 27: 05$, most alleles like; $\mathrm{B} * 27: 01, \mathrm{~B} * 27: 02, \mathrm{~B} * 27: 03, \mathrm{~B} * 27: 04, \mathrm{~B} * 27: 10$, $\mathrm{B}^{*} 27: 13, \mathrm{~B}^{*} 27: 14$, and $\mathrm{B} * 27: 15$ are known to be linked with AS [15]. In Caucasians, AS is associated with HLA-B*2701, *2702, $* 2705, * 2708$, and *2709, [16] in Chinese, HLA-B*27:04 and in Mediterranean population, it is HLA-B*27:02, whereas Asians have been associated with $B * 2704, * 2706$, and $* 2707$. The subtype B*2706 is now known as B*2722 is a rare subtype identified only in some Southeast Asian populations and B*2709 in Sardinians are unrelated to the expansion of AS $[16,17]$. $\mathrm{B}^{*} 2703$ is reported in African-Americans and West African populations, whereas HLA-B*27:02 is the predominant allele among the Middle East and Jewish populations [18-21]. In India, though there are very few studies connecting HLA-B antigen with the populace and clinical manifestations of AS, there are no reports of HLA-B genotype association to South Indian AS patients [22,23]

\section{MATERIALS AND METHODS}

\subsection{Sample Collection}

Selection criterion for the subjects included for the proposed study was that the successive AS patients were selected for the duration of 1 year. Rheumatologist evaluated all the patients and necessary radiographs, and clinical tests were performed to confirm the clinical status. Had new-onset back pain at age 16-45 and lasting more than 3 months. Cases with inflammatory low back pain for more than 3 months of duration with sacroiliitis on magnetic resonance imaging were included for the proposed study. Excluded subjects who had back pain lasting less than 3 months, isolated neck pain, or not meeting the symptoms related to AS.183 clinical samples (EDTA Blood) were used in this study. All the samples were taken from the patients who showed symptoms of rheumatoid arthritis (RA), AS like headache, neck and shoulder pain, back pain, pelvic pain, poor appetite, joint stiffness, and fever. All the samples were further processed in the Central Molecular Research Laboratory (CMRL), Shri Guru Ram Rai Institute of Medical and Health Science (SGRRIM \& HS), Patel Nagar, Dehradun (UK) for the molecular diagnosis of HLA-B27, RA factors, and other parameters. The samples (EDTA Blood) were collected from different IPD and OPD (medicine, neurosurgery,
Ortho, Pediatrics, ophthalmology, pediatrics, emergency, etc.) of Shri Mahant Indiresh Hospital, Dehradun and transported to CMRL, SGRRIM \& HS, Patel Nagar, Dehradun. Nucleic acid was isolated from whole blood by silica columns by QIAamp Blood DNA Mini (as per the manufacturer's protocol). DNA extraction was done from whole blood for HLA-B27 SSAP that was further subjected to serological and pathological parameters. Biochemical, serological, pathological, and molecular tests for all the 183 samples were done in Central Laboratory, SMIH.

\subsection{Method for PCR Protocol for SSAP}

PCR Buffer (10×) (Larova Cat \# Taq 500), SSP HLA-B27 PCR Kit, DNA 1: a B-27 positive DNA as a positive control, and nucleasefree water as a negative control DNA. Taq DNA polymerase (5 unit/ $\mu \mathrm{l}), 100$ bp DNA Ladder (Bangalore GENEI Cat \# MBD13J), Tris Base (Life Technology Cat \# 1000LT), EDTA (Amresco Cat \# 9572E), Agarose (Amresco Cat \# GR 100-LELT), Bromophenol Blue (Amresco Cat \# 0532), Gel loading dye, 1× TAE Buffer, Milli Q Water were used. PCR master mix completes with Taq contains DNA Taq polymerase: 0.4 units per $10 \mu \mathrm{l}$ SSP reaction, Nucleotides: Final concentration of each dNTPs is $200 \mu \mathrm{M}, \mathrm{PCR}$ buffer: Final conc. $50 \mathrm{mM} \mathrm{KCl}, 1.5 \mathrm{Mm} \mathrm{MgCl}_{2}, 10 \mathrm{Mm}$ Tris- $\mathrm{HCl}$ $\mathrm{pH} 8.3,0.001 \% \mathrm{w} / \mathrm{v}$ gelatin, Glycerol: Final conc. of glycerol is $5 \%$, and Cresol red: Final concentration of cresol red is $100 \mu \mathrm{g} / \mathrm{ml}$. The amplicon product of $430 \mathrm{bp}$ as an internal control indicates the validity of the PCR protocol, as well as the PCR product of 149 bp, confirms the presence of HLA B-27 SSA (Fig. 1).

\subsection{Ethical Approval}

The current study was approved by the ethical clearance of the SGRRIM \& HS, Patel Nagar, Dehradun, Uttarakhand, where this study was conducted. Informed written consent was obtained from all patients prior to their enrollment in this study.
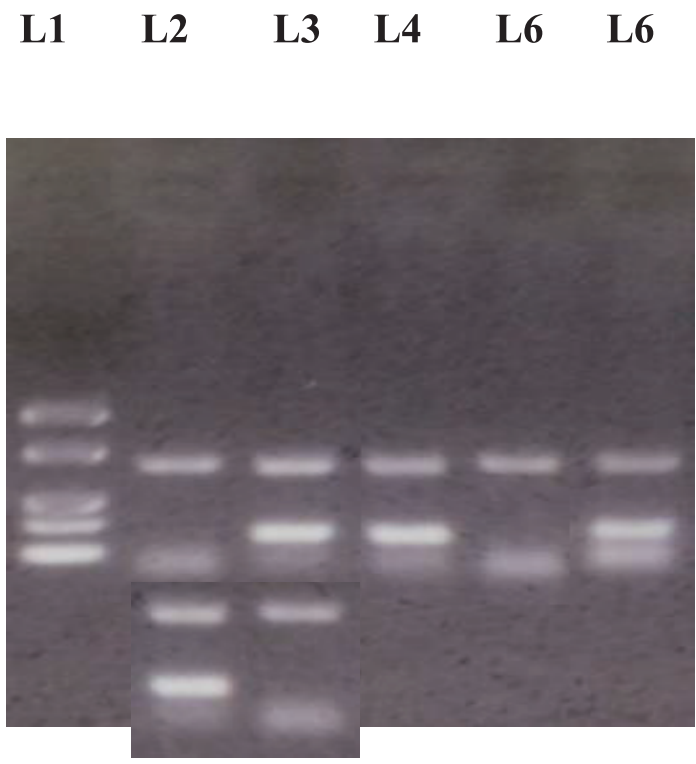

Figure 1: Agarose gel electrophoresis for SSAP for HLA B-27. L1. Different base pair DNA ladder, L2. Positive Control, L3. Negative control, L4. Sample 1 and L6. Sample 3 Positive For HLA B-27, L5.Sample 2 Negative. 


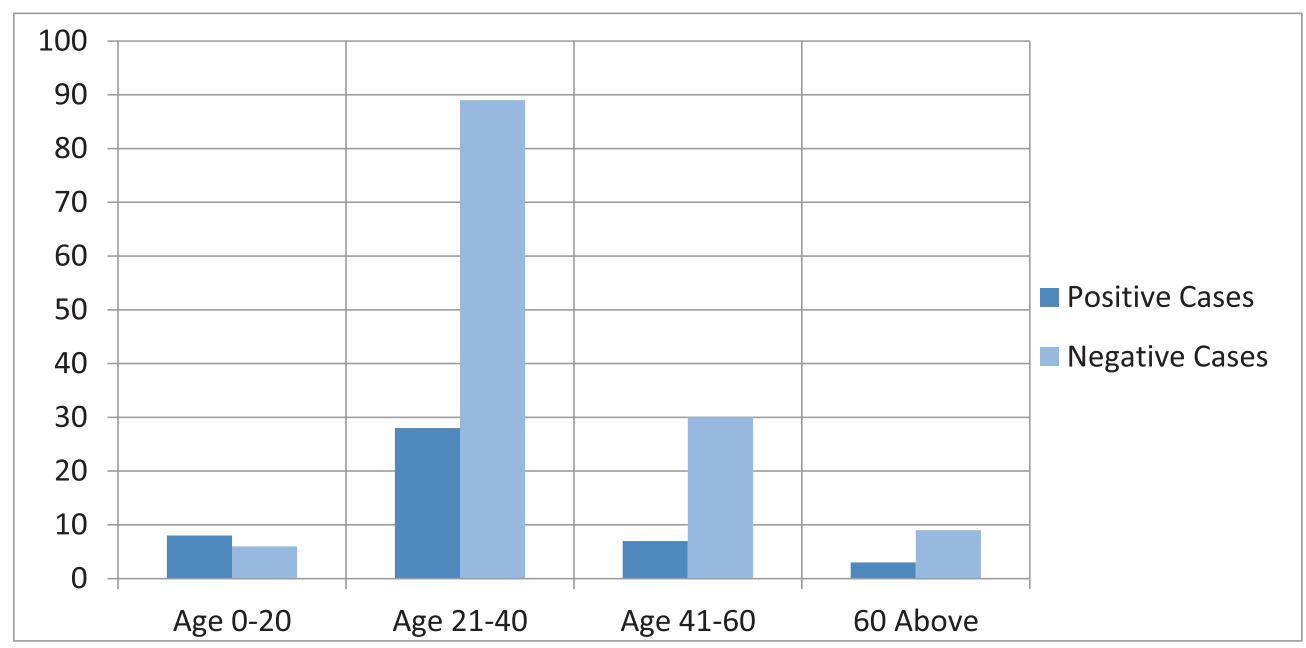

Figure 2: Age-wise distribution for HLA-B27 Gene.

\section{RESULTS}

Out of 183 total cases, $45(34 \%)$ cases were found to be positive and $138(66 \%)$ cases were negative. Out of 183 cases for HLA-B27, 63 cases were of female, in which 7 (4\%) cases were positive and $56(30 \%)$ were negative, whereas $38(21 \%)$ cases were positive and $82(45 \%)$ cases were negative for male. Biochemical investigations were done for the entire clinical specimen that involves RA factor, Vitamin D, and vitamin B12. It was analyzed that RA factor was found to be above the normal range (normal range; $0-20 \mathrm{IU} / \mathrm{ml}$ ) in 10 cases but the same were negative for HLA-B27 gene. For all the cases, Vitamin D and Vitamin B12 come normal. When studied with respect to the age group, the positivity rate of HLA B-27 SSA presence, the most affected age group was in between 21 and 40 years (Fig. 2).

\section{DISCUSSION}

Out of 183 samples collected for the proposed study, 45 samples showed HLA-B27 specific allele positive results, while the remaining 138 are negative. Appearance of 145-146 bp specific band indicates the presence of HLA-B27 gene. In the present study, the positivity rate of HLA-B27 specific allele in different age groups and gender-wise distribution of the HLA-B27 specific allele in patients using Multiplex PCR approach were determined. Forty-five (45\%) AS patients were found to be HLA-B27 specific allele positive, while remaining $138(75 \%)$ were negative. When samples were analyzed in terms of age groups, it was found that out of 45 positive samples, the positivity rate was maximum, i.e., $57.14 \%$ in the patients above 30 years of age. However, in the age group of 20-30 years, the positivity rate was $42.86 \%$. Furthermore, it was noticed in terms of gender-wise variation, five were men and the remaining two were women. There are certain parameters that were selected for the detection of HLA B27 and RA factor. The association of Vitamin D and HLA-B27 is a very important factor for the collaborative clinical manifestations in such cases and the study of the same is of utmost clinical relevance for the management of AS.
RA Factor: RA factor is responsible for the inflammation in the joints and restricted movements of various joints [24]. A person shows a considerable increase in the concentration from the normal range, the symptoms will be shown. A person who is suffering from arthritis can also suffer from AS and associated uveitis [25]. Vitamin D: The deficiency in vit. D can cause problems in bone. Bone density reduces and bone weakens due to deficiency of vit. D [26]. A person who has a low concentration of vit. D can show symptoms relating to spondylitis. Vitamin B12: Deficiency of vit. B12 causes anemia, which is one of the symptoms of the AS [27]. AS: It is a type of arthritis in which there is long-term inflammation of the joints of the spine [28]. Typically, the joints where the spine joins the pelvis are also affected. Occasionally, other joints such as the shoulders or hips are involved. Eye and bowel problems may occur. Back pain is a characteristic symptom of AS, and it often comes and goes. Stiffness of the affected joins generally worsens over time. Although the cause of AS is unknown, it is believed to involve a combination of genetic and environmental factors. More than $90 \%$ of those affected have a specific HLA known as the HLA-B27 antigen.

Uveitis is a common form of intraocular inflammation of the iris, ciliary body, or choroid, which presents predominantly as anterior uveitis [29]. Approximately 50\% of acute anterior uveitis cases are associated with the allele HLA B27. Acute anterior uveitis is the most common form of uveitis, accounting for approximately $90 \%$ of all cases. The disease is typically acute in onset, unilateral, no granulomatous inflammation involving the iris and ciliary body, with a tendency to recurrent attacks. Environmental factors play a critical role in the pathogenesis [30]. It has been well established that the association of the HLA-B27 antigen in $90 \%-95 \%$ of patients with AS is HLA-B27 specific allele positive. Identification of HLA-B27 by PCR supports the diagnosis of AS in symptomatic individuals and negative results exclude the diagnosis [31]. Various studies showed that $90 \%-94 \%$ of AS sufferers have HLA-B27 allele positive, while $5 \%-9 \%$ of the general population with AS may have other contributory factors for positivity of HLA-B27 [32-35]. 


\section{CONCLUSION}

$\mathrm{AS}$ is an autoimmune disorder that requires proper medication for the patients. When compared to flow-cytometry and serological methods, molecular tools and technologies, including PCR is a promising diagnostic method for the characterization of AS. The ease and allele specified detection protocols make it gold standard for the diagnosis of autoimmune disorders.

\section{CONFLICT OF INTEREST}

None.

\section{ACKNOWLEDGMENT}

The authors are grateful to Honorable Chairman, Shri Guru Ram Rai Education Mission for his kind support and guidance.

\section{REFERENCES}

1. Colbert RA, Navid F, Gill T. The role of HLA-B*27 in spondyloarthritis. Best Pract Res Clin Rheumatol 2017;31(6):797-815.

2. Ansari MA, Pedergnana V, Ip CL, Magri A, Von Delft A, Bonsall D, et al. Genome-to-genome analysis highlights the effect of the human innate and adaptive immune systems on the hepatitis $\mathrm{C}$ virus. Nat Gen 2017;49(5):666.

3. FitzGerald O, Haroon M, Giles JT, Winchester R. Concepts of pathogenesis in psoriatic arthritis: genotype determines clinical phenotype. Arthritis Res \& Ther 2015;17(1):115.

4. Brown MA, Kenna T, Wordsworth BP. Genetics of ankylosing spondylitis - insights into pathogenesis. Nat Rev Rheumatol 2016;12(2):81.

5. Taurog JD, Chhabra A, Colbert RA. Ankylosing spondylitis and axial spondyloarthritis. N Engl J Med 2016;374(26):2563-74.

6. Srivastava R, Agnihotry S, Aggarwal R, Bajpai P, Aggarwal A. HLA-B27 subtypes in enthesitis-related arthritis category of juvenile idiopathic arthritis and ankylosing spondylitis in northern India. Clin Exp Rheumatol 2015;33(6):931-5.

7. Ferrer A, Fernández ME, Nazabal M. Overview on HLA and DNA typing methods. Biotecnol Aplicada 2005;22(2):91-101.

8. Robinson J, Guethlein LA, Cereb N, Yang SY, Norman PJ, Marsh $\mathrm{SGE}$, et al. Distinguishing functional polymorphism from random variation in the sequences of $>10,000$ HLA-A,-B and-C alleles. PLoS Genet 2017;13(6):e1006862.

9. Hildebrand WH, McMurtrey C, Buchli R, Cate S. Selective anti-hla antibody removal device and methods of production and use thereof. U.S. Patent Application 13/860,897, September 19, 2013.

10. Abbas AK, Lichtman AHH, Pillai S. Cellular and molecular immunology E-book. Elsevier Health Science, 2014.

11. Lin L, Faraco J, Li R, Kadotani H, Rogers W, Lin X, et al. The sleep disorder canine narcolepsy is caused by a mutation in the hypocretin (orexin) receptor 2 gene. Cell 1999;98(3):365-76.

12. Anasetti C, Amos D, Beatty PG, Appelbaum FR, Bensinger W, Buckner CD, et al. Effect of HLA compatibility on engraftment of bone marrow transplants in patients with leukemia or lymphoma. $\mathrm{N}$ Engl J Med 1989;320(4):197-204

13. The International HIV Controllers. The major genetic determinants of HIV-1 control affect HLA class I peptide presentation. Science 2010;330(6010):1551.

14. Mahmoudi M, Aslani S, Nicknam MH, Karami J, Jamshidi AR. New insights toward the pathogenesis of ankylosing spondylitis; genetic variations and epigenetic modifications. Modern Rheumatol 2017;27(2):198-209.
15. Helbert M. Immunology for Medical Students E-Book. Elsevier Health Sciences, 2016

16. Taurog JD, Dorris ML, Satumtira N, Tran TM, Sharma R, Dressel $\mathrm{R}$, et al. Spondylarthritis in HLA-B27/human beta2-microglobulintransgenic rats is not prevented by lack of CD8. Arthritis Rheum 2009;60:1977-84.

17. Ma HJ, Hu FP. Diversity of human leukocyte antigen-B27 alleles in Han population of Hunan province, Southern China. Tiss Antigens 2006;68:163-6.

18. Hou TY, Chen HC, Chen CH, Chang DM, Liu FC, Lai JH. Usefulness of human leucocyte antigen-B27 subtypes in predicting ankylosing spondylitis: Taiwan experience. Intern Med J 2007;37:749-52.

19. El Mouraghi I, Ouarour A, Ghozlani I, Collantes E, Solana R, El Maghraoui A. Polymorphisms of HLA-A,B,Cw and DRB1 antigens in moroccan patients with ankylosing spondylitis and a comparison of clinical features with frequencies of HLA-B* 27. Tiss Antigens 2015;85(2):108-16

20. Smith JA. Update on ankylosing spondylitis: current concepts in pathogenesis. Curr Allergy Asthma Rep 2015;15(1):489.

21. Mou Y, Zhang P, Li Q, Lin Z, Liao Z, Wei Q, Gu J. Clinical features in juvenile-onset ankylosing spondylitis patients carrying different B27 subtypes. BioMed Res Int 2015; Article ID: 594878.

22. Radhia KB, Ayed-Jendoubi S, Sfar I, Romdhane TB, Makhlouf M, Gorgi Y, et al. Distribution of HLA-B*27 subtypes in tunisians and their association with ankylosing spondylitis. Joint Bone Spine 2008;75:172-5.

23. Shankarkumar U. HLA-B27 allele diversity in Indians: impact of ethnic origin and the caste system. Br J Biomed Sci 2003;60:223-6.

24. Kankonkar SR, Raikar SC, Joshi SV, Tijoriwala SJ. Association of HLA B27 antigen in Indian patients of ankylosing spondylitis and other autoimmune diseases. J Assoc Physicians India 1998;46: $345-50$.

25. Ogunshola F, Anmole G, Miller RL, Goering E, Nkosi T, Muema D, et al. Dual HLA B* 42 and B* 81-reactive T cell receptors recognize more diverse HIV-1 Gag escape variants. Nat Commun 2018; 9(1):5023.

26. McGranahan N, Rosenthal R, Hiley CT, Rowan AJ, Watkins TBK, Wilson GA, et al. Allele-specific HLA loss and immune escape in lung cancer evolution. Cell 2017;171(6):1259-71.

27. Harada SI, Rodan GA. Control of osteoblast function and regulation of bone mass. Nature 2003;423(6937):349.

28. FitzGerald O, Haroon M, Giles JT, Winchester R. Concepts of pathogenesis in psoriatic arthritis: genotype determines clinical phenotype. Arth Res Ther 2015;17(1):115.

29. Han C, Robinson DW, Hackett MV, Paramore LC, Fraeman KH, Bala MV. Cardiovascular disease and risk factors in patients with rheumatoid arthritis, psoriatic arthritis, and ankylosing spondylitis. J Rheumatol 2006;33(11):2167-72.

30. Chang JH, McCluskey PJ, Wakefield D. Acute anterior uveitis and HLA-B27. Survey Ophthalmol 2005;50(4):364-88.

31. Takeuchi M, Kastner DL, Remmers EF. The immunogenetics of Behçet's disease: a comprehensive review. J Autoimmun 2015;64:13748.

32. Marcilla M, Alvarez I, Ramos-Fernández A, Lombardía M, Paradela A, Albar JP. Comparative analysis of the endogenous peptidomes displayed by HLA-B* 27 and Mamu-B* 08: two MHC class I alleles associated with elite control of HIV/SIV infection. J Proteome Res 2016;15(3):1059-69.

33. Sharma N, Sharma V, Masood T, Nautiyal SC, Sailwal S, Singh RK, et al. Usage of conventional PCR technology for the detection of HLA-B27 allele: a significant molecular marker of ankylosing spondylitis. Indian J Clin Biochem 2013;28(2):189-92. 
34. Shahlaee A, Mahmoudi M, Nicknam MH, Farhadi E, Fallahi S, Jamshidi AR. Gender differences in Iranian patients with ankylosing spondylitis. Clin Rheumatol 2015;34(2):285-93.

35. Dashti N, Mahmoudi M, Aslani S, Jamshidi A. HLA-B* 27 subtypes and their implications in the pathogenesis of ankylosing spondylitis. Gene 2018;670:15-21.

\section{How to cite this article:}

Sharma N, Anas M, Rabbani A, Bharti P, Kaundal S, Kumar

$\mathrm{V}$, et al. HLA-B*27 subtypes and its clinical implications characterization by studying sequence specific alleles. J Appl Biol Biotech 2019;7(04):84-88. DOI: 10.7324/ JABB.2019.70413 